\title{
Encouraging Students with Different Profiles of Perceptions to Pursue Science by Choosing Appropriate Teaching Methods for Each Age Group
}

\author{
Patrice Potvin $^{1}$ - Abdelkrim Hasni ${ }^{2}$
}

Published online: 14 June 2017

(C) The Author(s) 2017. This article is an open access publication

\begin{abstract}
This research aimed at identifying student profiles of perceptions by means of a clustering method using a validated questionnaire. These profiles describe students' attraction to science and technology $(S \& T)$ studies and careers as a variable driven by school $S \& T$ self-concept and interest in school $S \& T$. In addition to three rather predictable student profiles (confident enthusiast, average ambitious, and pessimistic dropout), the fourth fairly well-populated profile called confident indifferent was produced. Our second and third research questions allowed us to describe each profile in terms of the instructional methods to which their population was exposed (including the degree to which they were actively involved) and the instructional methods to which they would like more exposure. An analysis of the evolution of the profiles' population over time is also presented. The results suggest that pedagogical variety and active involvement in the decision to pursue S\&T are important. The perception of the utility and importance of $S \& T$ both in and out of school may also play an important role in these decisions. Minor pedagogical preferences were also found in certain age groups.
\end{abstract}

Keywords Science $\cdot$ Technology Interest $\cdot$ Self-concept $\cdot$ Pursuing studies and career . Instructional methods

Patrice Potvin

Potvin.patrice@uqam.ca

Abdelkrim Hasni

Abdelkrim.Hasni@USherbrooke.ca

1 Département de didactique, Université du Québec à Montréal (UQAM), C.P.8888, Succ. Centre-ville, Montréal, QC H3C 3P8, Canada

2 Université de Sherbrooke, Sherbrooke, Canada 


\section{Context}

\section{Positive Constructs of Perceptions Have Positive Outcomes on Learning}

Over the years, numerous studies in the science education field have focused on the importance of the connection between students' perceptions and the content knowledge to be learned. Researchers used a wide variety of constructs to structure these research efforts. According to Potvin and Hasni (2014b), the main constructs used (from most to least common) are as follows:

1. Attitude is not always well-defined but usually consists of three components (affective, cognitive, and behavioral) and generally refers to Koballa and Crawley (1985)).

2. Interest focuses on the particular nature of the objects to be learned and often refers to Hidi and colleagues' work, "In person-object theory (Hidi and Renninger 2006; Renninger and Hidi 2011), interest is seen as a dynamic relationship between a person and a specific object. This object may be a generic object, such as the school subject of science, or it may be a specific scientific phenomenon or concept" (Olsen and Lie 2011, p. 99).

3. Motivation focuses on the goals or the reasons that explain the behavior and refers to Bandura's tradition of research. Most of the time, literature shows that researchers prefer the "intrinsic" aspect of motivation to that which is external to the object to be learned (grades, incentives, etc.) (Corpus and Wormington 2014, p. 496).

Other perceptual constructs have also been argued to improve our understanding of the learner/content interaction. For example, science self-concept (Taskinen et al. 2013), enjoyment (Ainley and Ainley 2011), identity as a scientist (Robnett et al. 2015), taste for science (Anderhag et al. 2015), and even pride and triumph (Bellocchi and Ritchie 2015) were used recently. In most cases, such constructs were either hypothesized or confirmed as having a major effect on learning or achievement in science (Bong et al. 2015; Corpus and Wormington 2014; Juriševič et al. 2012; Korpershoek and Kuyper 2015; Oliver and Simpson 1988; Olsen and Lie 2011; Singh et al. 2002).

Many of these constructs have also been studied to see how they predict each other. Most of the time, they do (Agranovich and Assaraf 2013; Bong et al. 2015; Glynn et al. 2015; Hasni and Potvin 2015), but not always strongly. This suggests that despite partially overlapping each other (or in some cases being the cause of each other), they also display certain fundamental disparities. However, regardless of the measured construct, positive links between learners' perceptions and content are most certainly and generally considered desirable from an educational standpoint.

\section{Perceptual Factors and the Intention to Pursue Science}

Perceptual factors were also found to have an impact on the possible attraction (or intention) to pursue further studies and a career in science. However, fewer constructs about perceptions were used, and it appears that individual interest and [science] self-concept are more common than other constructs - even more common than the usually popular attitude. It is not surprising that both of them are correlated with the intention to pursue science.

Interest is undisputedly the strongest predictor (Bong et al. 2015; Taskinen et al. 2013); however, self-concept (or self-efficacy) is also considered very important, although its role and fluctuations are less clear. In a strong longitudinal study, Bong et al. (2015) showed that self- 
concept is less stable over time than interest, and that interest is a better causal predictor of selfefficacy than the other way around. These results suggest that self-concept is more sensitive and less resistant to school experience than interest. Furthermore, in another longitudinal study, Robnett et al. (2015) showed that self-concept can be influenced by the quality of scientific research experience, which in turn predicts identity as a scientist. In the study, self-concept was understood as a mediator (p. 863) between scientific activities and identity as a scientist.

While self-concept appears to be more strongly correlated with interest in math and science than in any other subject matter, it is also more volatile. For example, some individuals have good self-concept without necessarily showing interest (Bong et al. 2015, p. 37). In other words, students who believe they are good - or feel strong - in S\&T compared to other students or compared to their own skill level in other areas do not necessarily feel drawn to the topic.

Nevertheless, self-concept is still considered very important, "most predictive" (Mau 2003, p. 240), "strong predictor" (Hasni and Potvin 2015, p.356), or "extremely salient" (Taskinen et al. 2013, p. 719), when it comes time to choose a career (Hackett 1995; Oliver and Simpson 1988). Bong et al. (2015, p. 33) also argue that, in the end, "students need both interest and self-efficacy to enter [...] science."

Unfortunately, research efforts have also shown that "while they follow their school paths, students generally see [science] as becoming more difficult and less gratifying (self-concept)" (Potvin \& Hasni 2014a, p. 796). The question of how to improve interest and self-concept in schools is therefore as important as ever.

\section{Perceptual Factors Can Be Improved Through Proper Instruction}

Many of the factors that predict perceptual constructs have nothing to do with school. While parent involvement and the motivational practices they use (Gottfried et al. 1994) are among the most important, some factors are specific to school science, such as the amount of time parents spend talking to their children about school science activities or how often the family attends science-based cultural activities (Hasni and Potvin 2015). No matter how strong the factors are, it might appear more difficult to exert an influence on them. Fortunately, what happens in school nevertheless appears to have an important impact on perceptual constructs. The quality and type of instructional methods and other "[...] school factors [are] highly relevant for students' interest in science and science self-concept" (Taskinen et al. 2013, p. 717). According to Turner et al. (2015), interest "is not an individual creation; it emerges from the interaction of teachers, students, and content" (p. 245). "Contextualization" (Hasni and Potvin 2015, p. 357; Potvin and Hasni 2014b) or focusing on "real-life applications" (Taskinen et al. 2013, p. 727), relevance, and meaningfulness (Turner et al. 2015 , p. 254) appear to be very important characteristics of instructional methods that develop factors that concern perceptions. Activities that are "challenging" and that allow students to "selfconfirm their understanding" also appear to have a very positive effect (Bellocchi and Ritchie 2015, p. 657). Finally, the "degree of student involvement" (Hasni and Potvin 2015, p. 357) in inquiry processes also appears to have positive outcomes (whereas simple practical work has less). In the same publication (Hasni and Potvin 2015), the same data as used in this study was used to identify participants' general pedagogical preferences. They included (from most to least popular) "observations, practical work, and experiments"; "projects"; and "field trips." Those that were least popular included (starting with the least popular) "mathematical calculations," "exercises in handouts or workbooks," and "oral presentations."

There is extensive research literature that strives to reveal or confirm what makes up motivating instructional practices. Few studies, however, look at the effects on perceptions 
that instructional practices have on different types of learners. Gender and age differences are occasionally explored but significant differences appear rather difficult to record (Belcheir 1998; Hasni and Potvin 2015). It remains plausible that certain motivational profiles of students can be explained by the instructional methods that were used with them or simply by the fact that they have different pedagogical preferences.

\section{Learners Respond Differently to Instruction}

“A given instructional enhancement might 'turn on' one student and 'turn off' another student at the same time" (Durik et al. 2015, p. 49). Along the same lines, Durik et al. (2015, p. 51) argues that " $[t]$ he challenge for researchers and teachers is to identify instructional enhancements that can maintain or amplify the motivation of those with existing high individual interest as well as cultivate the motivation of those with low individual interest", and Maltese and Harsh (2015) also insist that "simply put, merely because there is evidence that a given intervention works to increase interest for certain students does not mean that it will work for all their peers" (p. 219).

Such differences have been recorded in the past, for instance, "variables that catch attention by way of novelty, uncertainty, and humor may be more effective for raising situational interest of learners with low versus high individual interest" (Durik et al. 2015, p. 51). Hidi and Renninger also suggest that the level of interest can interfere in complex and unpredictable ways. They give the interesting and plausible example that "[w]ith more developed interest, the learner has more knowledge, and therefore information that is already known will not be a trigger for interest" (Hidi et al. 2015).

The relationship between perceptual constructs and certain instructional methods is probably more complex than merely linear, as implicitly suggested in most research efforts on the topic. We therefore suggest that it may be more fruitful to establish profiles of perceptions (using the most commonly used variables) than to merely consider scores.

\section{Research Questions}

1. What relevant S\&T profiles of perceptions of students can be established using cluster methods?

2. What can be inferred about the students with these profiles in terms of (a) other common perceptual constructs, (b) the instructional methods to which they have been exposed (and especially, (c) with which they have been given active responsibilities in learning?); and (d) the instructional methods to which they would like more exposure?

3. What is the distribution of students by an age group in these profiles?

The answers to these questions should help educators and politicians identify which methods to use and when in order to encourage students to seriously consider pursuing S\&T.

\section{Methods}

\section{Instrument}

We used CRIJEST's general questionnaire (GQ), which contains 139 questions on interest in science and technology and has been validated and used in previous studies (Hasni and Potvin 
2015; Potvin and Hasni 2014a). For feasibility purposes, the Likert-type questionnaire was originally split into two subversions: one for students whose last name begins with the letters A to $\mathrm{J}$ (called the AJ questionnaire) and the second one called KZ. About half of the questions were the same, and the other half was different. As a result, when the analysis looked at an item that only appeared in one questionnaire, it only accounted for half of the participants.

The GQ measures classical perceptual constructs such as interest in school $S \& T$, which is the average of the results from five selected items [101, 102, 103 (reversed), 104, and 105 (reversed) (Cronbach's $a=0.89)$ ]; importance of out-of-school $S \& T$, which is the average of the results from five items [28 (reversed), 29, 30,31, and 32 (Cronbach's $a=0.76$ )]; utility of outof-school $S \& T$ for society, which is the average of the results from four items [24, 25, 26, and 27 (Cronbach's $a=0.68)]$; utility of school $S \& T$ for everyday life, which is the average of the results from four items [109 (reversed), 110,111, 112 (Cronbach's $a=0.65$ )]; easiness of school $S \& T$, which is the average of the results from six items [52, 63, 64, 65, 66, and 67 (all reversed) (Cronbach's $a=0.83$ )]; school $S \& T$ self-concept, which is the average of the results from six items $[18,19,20,21,22$, and 23 (reversed) (Cronbach's $a=0.82$ )]; and attraction to $S \& T$ studies and careers, which is the average of the results from six items [130, 131 (reversed), 134, 135 (reversed), 136, and 137 (reversed) (Cronbach's $a=0.91$ )]. Given alphas are calculated using all available answers. For a complete list of these items, see Potvin and Hasni (2014a).

We will however only use interest in school $S \& T$ and $S \& T$ self-concept to determine a cluster solution as these are the most frequently used constructs in research efforts about the attraction to $S \& T$ studies and careers. This will provide a better basis of comparison with other existing studies. The other perceptual constructs will nevertheless be used later on to describe the characteristics of each student profile.

The questionnaire also contains instructional method frequency scales and pedagogical preference questions. For instance, the frequency question "In S\&T classes, we [do projects]" used a six- (and occasionally four-) point scale ranging from "never" to "very often." Other frequency scales were added to determine how often teachers give students active responsibilities in class. For instructional method preferences, questions like "In S\&T, I would like to do more [oral presentations]" used a six-point scale ranging from "strongly disagree" to "strongly agree."

These frequency and preference scales were used to test the following instructional methods: "listening to the teacher giving explanations at the front of the class," "making observations and doing practical work and experiments," "giving oral presentations," "learning by discussing with other students and the teacher," "using textbooks or websites," "exercises in handouts or workbooks," "projects," "field trips (museums, parks)," "hosting guest speakers who talk about science or careers," "watching documentaries," "participating in science fairs with the teacher's support," and "doing mathematical calculations." These instructional methods were selected by a panel of two science education specialists based on those found in important articles (Juuti et al. 2010; Owen et al. 2008; Swarat et al. 2012). They were also asked to choose methods that were representative of Quebec S\&T classes without being too heavy. Frequency scales were used to test the active participation when "encouraged to propose scientific explanations to other students and the teacher," "helping choose problems to be solved (during experiments or when building technical objects)," and "choosing which steps to take" and "which materials to use." Three scales about "looking for new information (in books or online)," "doing experiments or practical work," and "analyzing results" used a six-point frequency scale ranging from "the teacher always does it" to "I'm always the one who does it" to show what the teacher does versus the students. 


\section{Participants}

The participants (Table 1) consisted of 1451 French-speaking girls and 1189 Frenchspeaking boys [total $N=2640$ usable questionnaires (with consent)] in grades 5 through 11 from 40 greater Montreal schools that belong to five of Quebec's biggest school boards. The directors of educational services from these school boards, academic advisors, and elementary and science teachers identified these students as being "typical or representative" classes. The questionnaire was administered during class time with the permission of the teachers who agreed to make up for the lost time during other periods. Once the classes were identified, the teachers were instructed to play a short video about the project and read the instructions out loud to the class. The students were then given approximately $30 \mathrm{~min}$ (and sometimes a little more) to complete the questionnaire. While the teachers were instructed not to influence the students, they were also told they could offer help when asked.

\section{Analysis}

To answer the first research question, $k$-means clustering was obtained using the two-step function in the IBM SPSS Statistics 22.0 software. k-means clustering is a "method of cluster analysis that aims to partition $\mathrm{n}$ observations into k clusters in which each observation belongs to the cluster with the nearest mean" (Juriševič et al. 2012, p. 240). Cluster analysis is also defined as a "generic term for methods aiming to cluster individual cases (or variables) into larger groups, which at the same time are similar to cases within the group and dissimilar to cases outside the group. These properties of a cluster can be referred to as internal cohesion and external isolation" (Olsen and Lie 2011, p. 103). Also, refer to Baram-Tsabari et al. (2009, p. 1008) for similar definitions in science education research in which the Euclidean distances are used to establish cohesion and isolation. This method was also used successfully for studies that strive to establish clusters of magnitudes (Juriševič et al. 2012; Korpershoek and Kuyper 2015) or types (extrinsic/intrinsic) (Corpus and Wormington 2014) of motivation, different orientation profiles (Baram-Tsabari and Yarden 2009), and even "green"/techno/interest preference profiles (Haste 2004).

Unfortunately, according to Olsen and Lie (2011), "There is no clear advice in the literature for how to document the validity of a cluster analysis" (p.106). They do however suggest the following criteria to determine the validity of procedures of this type:

- "A stable cluster structure is not affected by the removal of a few points [...];

- the clusters obtained in [the] analysis are comparable to similar studies undertaken on similar kinds of datasets;

- the stability of the method is studied by carrying out the analysis with other proximity measures and other clustering methods; and

Table 1 The participants

\begin{tabular}{lllllllll}
\hline Grade & 5 & 6 & 7 & 8 & 9 & 10 & 11 & Total \\
\hline$N$ & 310 & 419 & 506 & 151 & 607 & 459 & 188 & 2640 \\
$\%$ & 11.7 & 15.9 & 19.2 & 5.7 & 23.0 & 17.4 & 7.1 & 100.0 \\
\hline
\end{tabular}


- it should be possible to conceptualise the clusters by some overarching and unifying concept that in turn may be reflected by a descriptive label" (Olsen and Lie 2011, p. 106).

Our clustering solution was obtained by exploring the different possible combinations of the characteristics identified as being the most important and relevant in the context section, namely $S \& T$ self-concept, interest in school $S \& T$, and attraction to $S \& T$ studies and careers.

To answer questions $2 \mathrm{a}$ to $2 \mathrm{~d}, t$ tests were performed for each factor or item comparing students from each profile with students that do not belong to it in order to see how these students differ from the rest and not how they differ from each other, like a general one-way ANOVA could have done. We also sometimes performed $t$ tests between clusters when it helped explain major differences between "cousin clusters." This was done using the ANOVA procedure. A MANOVA analysis was not possible since the participants did not answer every item (there were two questionnaires: AJ and KZ). To avoid type 1 errors (incorrect rejection of a true null hypothesis), we focused on results for which $p<.01$, instead of the usual $p<.05$. However, we did not completely exclude cases when $.01<p<.05$ from the discussion, but included them with much caution (also because lowering the signification threshold can increase type 2 errors). We also calculated and included Cohen's $d$ s in the discussion. This allowed for a description that shows both statistical significance and a substantial effect size.

Finally, to answer question 3, we created a percentage diagram to give an overview of the distribution of students from each profile. For the sake of clarity, we grouped the elementary students (grades 5 and 6) together, those in early secondary school (grades 7, 8, and 9), and those in late secondary school (grades 10 and 11). This gave a general idea of relatively equally populated groups without the small and statistically more fragile year-to-year variations that are not necessarily insightful for educators.

\section{Results and Interpretation}

\section{Establishing Profiles (Clusters) (Research Question 1)}

The first two-step cluster analysis examined interest in school $S \& T$ (ISS) and attraction to $S \& T$ studies and careers (ASC). The result was two rather predictable clusters, where ISS and ASC were either both high or both low. Constraining the analysis to produce three and four clusters only leads to the addition of intermediary clusters, confirming the collinearity of the two constructs already reported in the literature (see the context section). It also weakened the structure cohesion.

The second two-step cluster analysis involved S\&T self-concept (SSC) and ASC. The results were a little surprising, as a four-cluster solution was produced without constraining the number of clusters. Figure 1 describes the distribution of participants within the four profiles for each one of the two relevant variables and the numbers as well as percentages of participants within each cluster. The total number of participants does not entirely fit the total number of tested participants due to a few missing answers. The Silhouette measure of cohesion and separation was 0.50 , which is between fair and good (Kaufmanm and Rousseeuw 2009). This clustering solution therefore suggests a more complex than linear relation between ASC and SSC seeing that it created an unusual but rather well-populated cluster (26.9\% of all participants) with high SSC and low ASC (cluster 2, Fig. 1) with fairly interesting participant distribution among the clusters (approximately a quarter in each). 


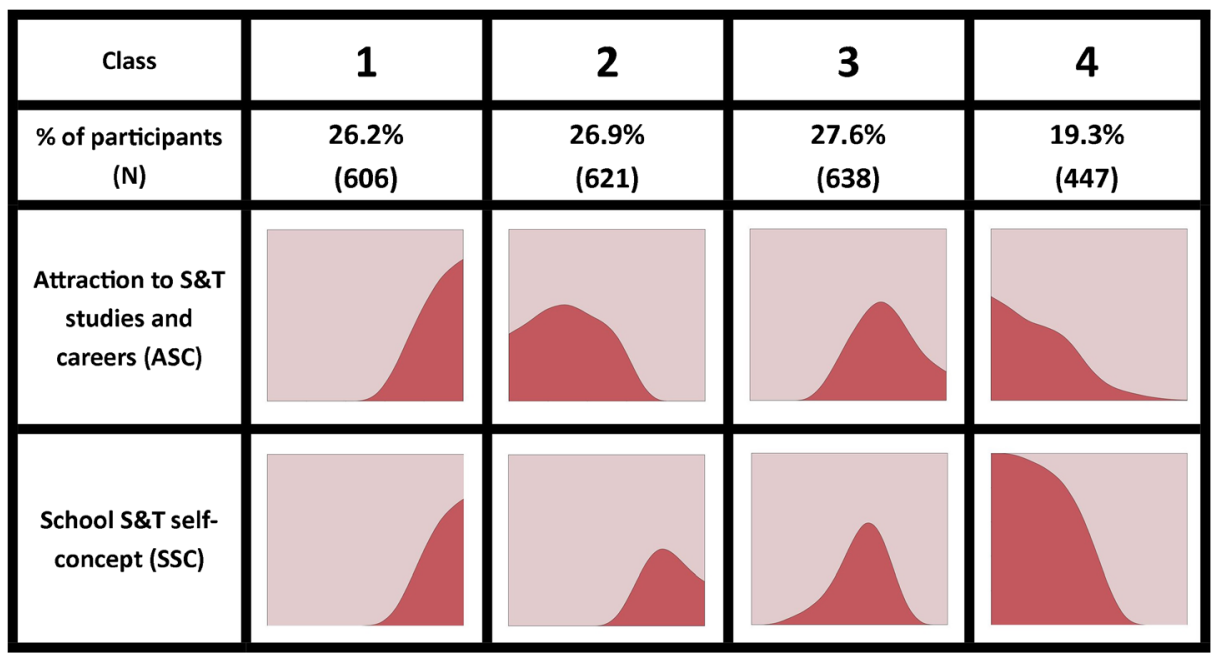

Fig. 1 Relative distribution of participants in the ASC/SSC cluster solution

Limiting it to more clusters did not produce an interpretable solution but weakened the structure cohesion and created a distribution of participants that was even less even.

The third two-step cluster analysis involving all three variables was conducted and revealed a rather unsurprising two-cluster solution where the factors were either all weak or all strong. Constraining the analysis to three clusters only added an intermediary cluster. Constraining the analysis to four clusters added a similar pattern as with the previous analysis, however, with a weaker Silhouette measure of cohesion and separation (fair 0.4) and with fewer participants (ISS only appeared in the AJ questionnaire). Constraining more clusters did not make it easier to interpret and lead to weakened structure cohesion. In light of these observations, we decided to pursue our analysis using the results from the second cluster analysis (Fig. 1).

This cluster analysis meets Olsen and Lie's criteria for a valid solution: (1) our cluster solution withstood the removal of as much as $30 \%$ of participants (removed at random); (2) the clusters obtained allowed us to better understand similar results using similar kinds of datasets because they explain why self-concept is less correlated with attraction to studies and careers than interest, all the while remaining relevant; (3) we conducted other cluster analyses with proximity constructs (like perceived easiness of $S \& T$ in the place of self-concept) and equivalent patterns were produced (we also tested our data with a hierarchical cluster method with convergent results); and (4) the clusters could be conceptualized by unifying concepts that in turn were easily given intelligible and relevant descriptive labels. These labels appear in the next section as subtitles as we proceed to a more thorough description of each profile. The established profiles allowed us to perform ANOVAs on all constructs and items, which were all found to be statistically significant, except for items about the desire for more observations, practical work, and experiments and projects. Some of the relevant post hoc results from this procedure were also used to discuss interesting differences between certain profiles with important similarities.

The Four Profiles (Research Questions 2a, b, c, and d)

The following paragraphs contain written (instead of large tables) descriptions and $t$ test results. Except in cases when explicit specifications are given, the expression "significant" 
will always mean that the results from $t$ tests produced a $p$ value equal to or less than .01 . When "large", "medium", and "small" are used to describe the significant differences observed, they will always systematically refer to Cohen's standards, in which the $d$ values are greater than 0.8, 0.5, and 0.2, respectively (Cohen 1988). With the exception of a few thoroughly discussed results, all differences presented between participants from our profiles (compared to all others) can be presumed to conform to both criterions of significance and of at least small magnitude. All differences that conform to this twofold requirement are included in the discussion as well as those that do not simply appear in the descriptions, except for a few relevant cases where the lack of possible contrast could make a point. When useful, a few interesting differences between neighboring profiles (instead of one profile vs. the rest of participants) are included in the descriptions (with the ANOVA procedure).

\section{The Confident Enthusiast (Cluster 1)}

Just over a quarter (26.2\%) of the participants can be qualified as "confident enthusiasts," i.e., having very strong school $S \& T$ self-concept and attraction to $S \& T$ studies and careers. $t$ tests reveal that they differ greatly from participants in the other clusters $(d=2.77$ and $d=3.77$, respectively). They present at least large and positive differences in interest, perceived easiness, and preference of $S \& T$ over other subjects. These students are also largely more convinced of the importance and utility of out-of-school $S \& T$ and of the utility of school $S \& T$ for real life (medium effect). This cluster has significantly more boys than girls, although this difference is below small. These students appear to be almost unconditionally positive about S\&T.

There are almost always small positive frequency differences in the instructional methods and experiences that students from this cluster were subjected to. They claim to do more observations, practical work, and experiments; discussions; [consulting of-] textbooks and websites; projects; field trips, hosting guest speakers; watching documentaries; and participating in science fairs. They also claim to do more mathematical calculations and to listen more often (than others) to the teachers' explanations. Oral presentations are the only item with no difference in frequency. These results are somewhat puzzling as it would seem impossible for students from cluster 1 to do more of all of these activities since they spend the same amount of time in school as other students. This very positive result may therefore be due to a bias for S\&T schooling or to the students being more sensitive to what happens in their S\&T class. Another hypothesis is that these students had more exposure to active instructional methods. Indeed, while our list of items covers a large number of instructional methods, it is not representative of the usual distribution of time in class but rather of all the possibilities that active methods can provide. Another argument in favor of this interpretation is that these students scored higher (small effects every time) in all seven items about the active role of students (proposing explanations, choosing problems to be solved, choosing which steps to take and materials to use) and in the three items comparing responsibilities [what students do vs. what the teacher does (see Instrument section for these items)]. We also believe that our positive results could also be partly attributable to exposure to a wider variety of instructional methods.

According to the results for the instructional methods to which confident enthusiasts would like more exposure, there are small (and positive) differences (compared with all other students) regarding discussions, watching documentaries, and science fairs but also oral presentations, mathematical calculations, and listening to the teacher's explanations. 
Considering the average student's aversion to the last three methods on this list (Hasni and Potvin 2015), it is not hard to imagine that positive differences merely mean that cluster 1 students are more resilient to these methods or that their teachers found ways to make these activities more enjoyable.

We therefore believe that in order to (should we ever want to) encourage confident enthusiasts to pursue $S \& T$, the $S \& T$ classrooms would have to remain status quo, except for a possible increase in discussions, documentaries, and science fairs.

\section{The Confident Indifferent (Cluster 2)}

A fairly large proportion (26.9\%) of our participants can be labeled as being confident indifferent. In this cluster, there was no statistical difference between boys and girls. This cluster is the most surprising: the students have a high $S \& T$ self-concept but no intention to pursue S\&T studies or careers, and yet they have no statistically significant difference in interest from the others. Nonetheless, compared to all other students statistically, they have large advantages in self-concept (and in perceived easiness) all the while having a strong aversion $(d=-1.69)$ to eventually pursuing S\&T. One hypothesis for this rejection might be found in the negative, yet small, distinction when they answer items regarding the utility of $S \& T$ for real life and the importance of out-of-school $S \& T$. Another hypothesis might be in the answer given to our questions about their preference of $S \& T$ over [other school subject] and therefore to the fact that they simply might be more drawn to "other than science" disciplines $(d=-0.32)$.

When comparing confident indifferent students with other students as a whole, there was no frequency difference in any instructional methods, except projects, which they have done slightly less frequently (small). Furthermore, there were no detectable differences in their desire for instructional methods. Our analysis therefore does not provide educators with any clues about what they can do in class to attract these students to studies and possible careers in S\&T besides working on convincing them about the importance and utility of $S \& T$. This may be the key to convince this group of students that S\&T studies and careers are worth a try.

We also believe that confident indifferent students are mainly responsible for the fact that the $S \& T$ self-concept is not as good a predictor of attraction to $S \& T$ studies and careers as interest.

\section{The Average Ambitious (Cluster 3)}

ANOVA tests cannot confirm that cluster 3 students (27.6\% of our participants) are different from cluster 2 students in terms of interest in school $S \& T$ (or from all other students, according to $t$ tests). However, their self-concept $(d=-1.06)$ and perceived easiness $(d=-0.33)$ are weaker than the rest of participants. Under these circumstances, it is surprising that they are much more attracted to S\&T studies and careers $(d=0.92)$. This could be partially explained by their more, yet small positive perception of the importance of out-of-school $S \& T(d=0.19)$. Unfortunately, no other constructs, nor our items about instructional method frequency or desire, provide insight on what makes this cluster different from the rest. In fact, these students seem to have been exposed to average instructional methods in the past and display usual pedagogical preferences for future experiences. This cluster contains a significantly higher number of young girls than boys but to a lower than small extent $(d=-0.10)$. 
We call these students average ambitious because they are difficult to distinguish from the rest of students, all the while still being fairly attracted to S\&T studies and careers. We also call them this because they are slightly more dispersed in terms of self-concept than the other clusters (see Fig. 1), which suggests that their positive - and somehow difficult to explain — large ASC holds this cluster together. Since the fundamental difference between these students and the confident indifferent group appears not to be in terms of interest nor in self-concept, it is possible that the importance of out-of-school $S \& T$ variable plays an important (and possibly causal) part in the very large difference between clusters 2 and 3 in terms of intentions to pursue.

\section{The Pessimistic Dropout (Cluster 4)}

The students in cluster 4 (19.7\% of participants) had negative results for most constructs. It is not surprising that both their $S \& T$ self-concept and their attraction to $S \& T$ studies and careers have negative differences compared with others students. But these differences appear to be of very large magnitude ( $d=-2.48$ and $d=-1.67$, respectively). These students largely prefer other subjects to S\&T $(d=-1.15)$. They find S\&T very difficult (easiness $d=-1.00)$. They do not find S\&T useful for their personal life $(d=-0.57)$ or their out-of-school life $(d=-0.62)$, and they find it to be largely unimportant $(d=-1.09)$. Basically, they are largely uninterested in S\&T $(d=-1.00)$. This cluster has more young girls than boys (difference of small magnitude).

With regard to the instructional methods to which these students have been exposed, all items show negative and small or medium differences, except mathematic calculations and exercises in handouts or workbooks. This suggests that the pedagogy they were exposed to lacked variety and active involvement most of the time. In fact, all seven items about active involvement also had negative differences (small and medium) compared with those in students from other clusters, including the three items that compare what students do with what the teacher does. Compared with other students, this cluster strongly perceives S\&T schooling as mainly passive activities, exercises, and calculations.

When asked what they would like to see more of in S\&T classes, their answers were often no different (according to our criteria) from the students in the other clusters, except for oral presentations, textbooks and websites, and science fairs, which had small and negative preference differences. Finally, and not surprisingly, they also expressed that they would like to have less exercises in handouts or workbooks and mathematical calculations (small differences).

It is possible that our "pessimistic dropout" students have such a negative bias towards S\&T that it negatively contaminated other items. However, upon examining their results as a whole, there are interesting divergences between certain items that suggest that they probably took the questionnaire seriously. In that case, it would be difficult not to at least partially blame their attitude on instructional methods. This is different from cluster 2 students for whom the instructional method frequency and desires were difficult to distinguish from those of other clusters.

\section{Distribution of Students in the Different Age Groups from the Four Profiles (Research Question 3)}

Figure 2 provides an overview of the distribution of students from each profile in the different age groups. 


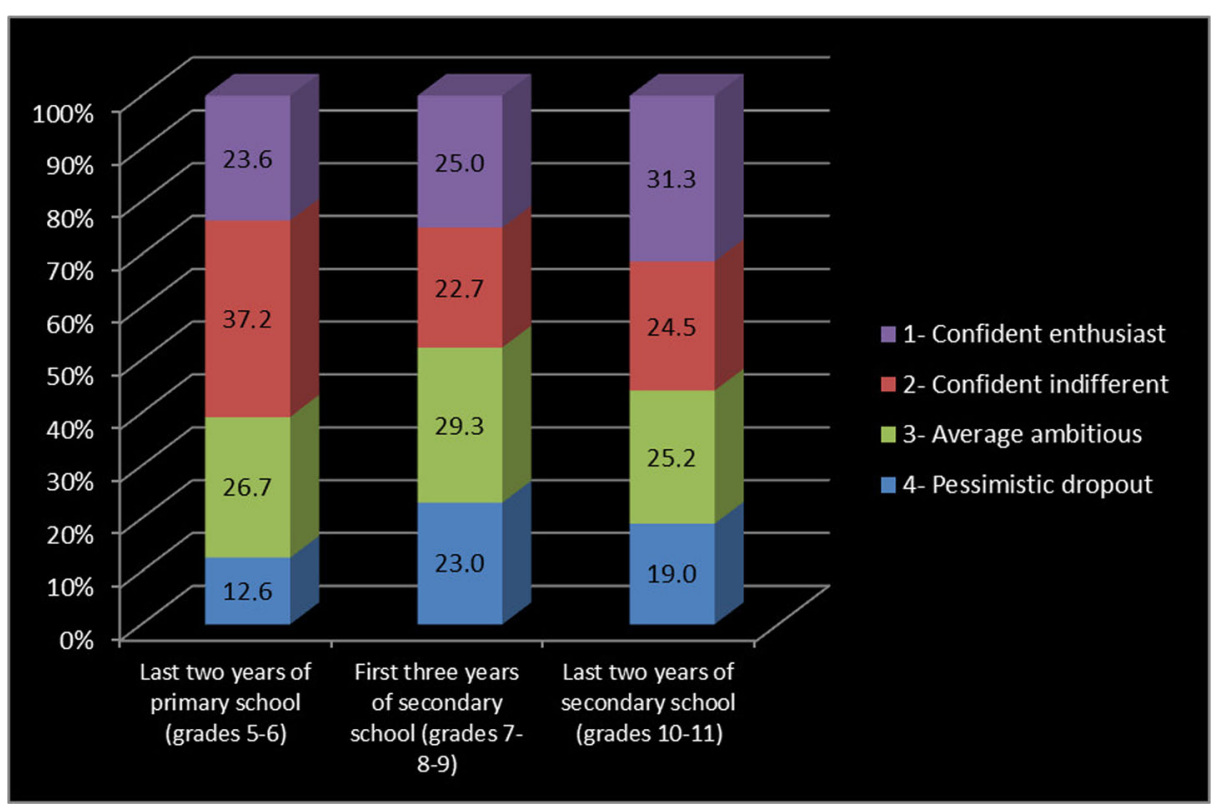

Fig. 2 Percentages of students for each cluster in the different age groups

\section{Discussion}

In this research, we tried to go beyond simply establishing linear relationships between the most commonly used variables that best describe the intentions to pursue. Our four-cluster solution allowed us to confirm that this underlying hypothesis was correct, at least in the case of science and technology self-concept. Indeed, while interest clearly has proportional effects on ASC, students with high self-concept are not necessarily as drawn to S\&T studies and careers. Some of them form a special, fairly well-populated $(26.2 \%)$ category with a fairly strong self-concept and a stronger inclination for other subject matters. This cluster, we believe, might explain why self-concept was not as clearly predictive as interest in other research efforts. While our research supports that "students need both interest and self-efficacy to enter [...] science" (Hasni and Potvin 2015, p.33), it is not clear that students need both a weak self-concept and weak interest to reject the possibility. Also, some students (like those in cluster 3) do not seem to need the best self-concept scores to seriously consider studies and careers in S\&T.

We believe that our cluster approach, especially given that an important and rather unexpected cluster (cluster 2) was revealed, is interesting in that it shows that simpler methods that presume linearity have limits and might not be ideal for identifying the best instructional methods for all types of students.

\section{The Perceived Importance and Utility of S\&T}

Our cluster solution was based on $S \& T$ self-concept and attraction to $S \& T$ studies and careers. It is therefore trivial that these constructs display convergent differences among clusters. It is not surprising that perceived easiness of school $S \& T$ generally goes hand in hand with selfconcept and, as previously discussed, interest in school $S \& T$, with attraction to $S \& T$ studies and careers. Perhaps, a little more unexpected are the effects of perceived utility and 
importance of out-of-school science and utility of school $S \& T$ for real life. Differences in these constructs appear to be explanatory of the gap between confident enthusiastic and confident indifferent participants, not just when compared using ANOVAS but also when compared with all non-belonging participants (for instance, when $t$ tests are performed with cluster 1 and noncluster 1 participants). Confident indifferent participants can also be (negatively) distinguished from average ambitious participants in perceived importance, although they have undistinguishable self-concepts. As for pessimistic dropouts, their negative distinction for these matters (all of large magnitudes) is not surprising. We therefore believe that our cluster method allowed us to understand that perceived importance and utility could benefit from further investigation should we want to encourage students to consider pursuing S\&T. It is possible that the importance of such constructs had been somehow overlooked in the past because of the noise that the less-than-linear behavior of self-concept might have bring to correlational studies. We believe this interpretation supports the hypothesis that contextualized teaching approaches which make strong links between school S\&T and real life (AllaireDuquette et al. 2014; Krapp and Prenzel 2011; Potvin and Hasni 2014b) could help encourage students to pursue S\&T. It also reminds teachers to think about ways to convince their students of the tangible consequences that S\&T can have on their everyday lives and on society in general.

\section{Comments About the Instructional Methods to Which Our Participants Were Exposed}

Our analysis was unable to establish distinctions in the instructional methods to which students from clusters 2 and 3 were exposed, except projects, which confident indifferent participants appear to have done less of. We therefore believe that our results support our conclusion that perceived importance and utility could be a key difference in the attraction to $S \& T$ studies and careers. Projects could also potentially convince students that S\&T is useful and important for real-life issues.

Our findings are more conclusive when confident enthusiasts are compared with pessimistic dropouts. The differences are more striking: confident enthusiasts appear to have been exposed to a much wider variety of instructional practices, including many that are non-traditional. They also had more exposure to students' preferred methods, such as observations, practical work, and experiments (Hasni and Potvin 2015), but paradoxically, also to those usually less popular, such as mathematical calculations and teacher's explanations. These students were also given active roles in learning (choosing which steps to take, being encouraged to propose explanations, etc.) more often than others (and not only more often than cluster 4 students).

Pessimistic dropouts had a much more traditional educational background. All instructional method items have small (but also sometimes medium) negative differences, except for mathematic calculations and exercises in handouts or workbooks. We therefore believe that these results are due to a lack of variety and a clear focus on some of the least popular methods (Hasni and Potvin 2015). It is therefore not surprising that these students perceive their role in class as passive (based on the results from items about active involvement) and that their teachers have more decision-making power on what happens in the class.

We believe that our analysis, especially that about clusters 1 and 2, is in line with many results reported elsewhere about the importance of instructional methods for the development of positive perceptions and the desire to pursue. The effects of novelty, active involvement, and 
the use of non-traditional methods appear to produce both positive and (sometimes very large) negative effects on certain students. However, since our intermediary and very well-populated (total of $54.5 \%$ of our participants) clusters (clusters 2 and 3) do not seem to be distinguishable from other students in terms of their exposure to instructional methods, we must acknowledge that pedagogical choices might not have much of an effect on them. Of course, students from clusters 2 and 3 could be converted into cluster 1 students (or students from cluster 4 to other profiles), but in this case, we believe that simply increasing the variety and using popular methods, such as observations, practical work, and experiments; projects; and field trips, could be beneficial.

\section{Comments About the Instructional Methods to Which Our Participants Would Like More Exposure}

We believe that our analysis of the "instructional methods to which our participants would like more exposure" items sheds light on how to encourage students to pursue $\mathrm{S} \& \mathrm{~T}$. However, as this is the case of the frequency of instructional methods, the analysis of their desire for certain instructional methods does not allow us to differentiate between the students in clusters 2 and 3. This further suggests that ordinary preferences could contribute to their interest and ASC. However, we find interesting differences in clusters 1 and 4. Confident enthusiasts, for instance, appear to want more oral presentations, calculations, and teacher explanations. As these methods are usually among the least popular, we believe that either students from these profiles are more resilient to these methods (student-based hypothesis) or their teachers make these activities more interesting. We believe that further investigations about these particular students are needed to weigh the relative importance of these hypotheses and how resilience or "interesting" oral presentations, calculations, and listening are experienced and can be generated. To secure the presence of confident enthusiasts (cluster 1), we suggest having more discussions, documentary viewing, and science fairs, as they seem to prefer these more than non-cluster 1 students. On the other hand, pessimistic dropouts, as for their expressed pedagogical desires, are not easily distinguishable from other students, except when it comes to oral presentations, using textbooks or websites, and science fairs, which seem to be the least popular. We would therefore advise against using these instructional methods should educators wish to reduce the number of cluster 4 students.

Based on our analysis of each cluster's pedagogical frequencies, desires, and other constructs, we suggest the following course of action to make students attracted to or more attracted to S\&T studies and careers: (a) use a wider variety of instructional methods and actively involve students; (b) enhance the perceived importance and/or utility of S\&T for real life; (c) use more instructional methods such as observations, practical work and experiments, and fields trips; and possibly (d) projects. For cluster 1 students, it could be beneficial to (e) continue using oral presentations, calculations, and teacher explanations, as they are popular with these students. Increasing the discussions, documentaries, and participation in science fairs should also be considered for these students. To decrease the population of cluster 4 students, it might be more pressing to (f) have less oral presentations, consult less textbooks and websites, and participate in less science fairs. Based on our research, Fig. 3 integrates our previous suggestions (a through $\mathrm{f}$ ) and shows our interpretation of what educators should focus on if they want to encourage their students (or some of their students) to migrate to a more positive cluster. 
Fig. 3 Helping students move from one cluster to another (refer to the preceding text for a more thorough interpretation of $a$ through $f$ )

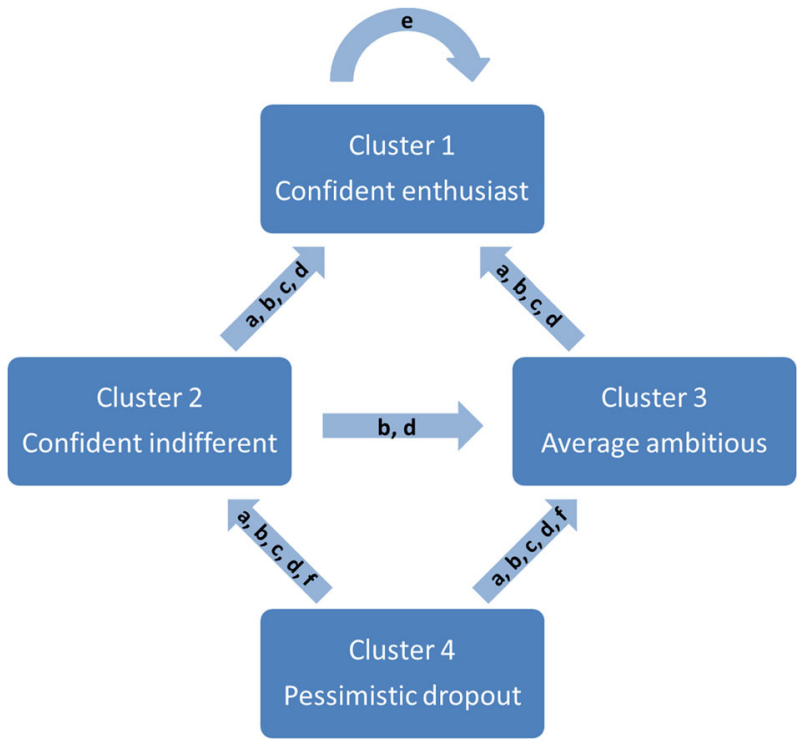

\section{Comments About the Evolution of Clusters Among Age Groups}

The most interesting "evolution" in age groups of the cluster populations (see Fig. 2) is the decrease in the cluster 2 (confident indifferent) population between primary and secondary school. This is most likely in favor of cluster 4 (pessimistic dropouts) since there is an almost equal increase in the latter. The most important difference between these two profiles is in selfconcept. We therefore suggest that some students who say they are not interested in S\&T studies and careers go from saying "but I'm nevertheless good at S\&T" at the elementary school level to saying "I'm not good at S\&T anymore" when they are in the first years of secondary school. Some hypotheses we can make about this possible change are that (1) their school experiences in early secondary courses are felt as demotivating or detrimental or as Anderhag suggested (Anderhag et al. 2015), (2) the high level of interest expressed at the primary level might simply be because they enjoyed the superficial aspects of rather poorly "scientific" activities. Under this hypothesis, the students' overestimated interest in science measure suffers when they face the demanding science courses at the secondary level.

It is however reassuring to see a growing importance of the population of cluster 1 (confident enthusiasts) in the higher grades and a decreasing importance of the population of cluster 4 (pessimistic dropouts) at the later secondary levels. This appears to be in line with earlier analyses (Potvin and Hasni 2014a).

It would however appear to be a little too risky to interpret smaller variations of Fig. 2 since the nature of this research is transversal and not longitudinal. A longitudinal study would have allowed us to carefully compare the profiles; nevertheless, since it would appear unlikely that many pessimistic dropouts made the radical change to become confident enthusiasts, we can suggest that some of the average ambitious became confident indifferent at the secondary level because they grew interested in other non-scientific studies and professions. This hypothesis seems reasonable since the self-concept of students from these clusters is rather similar, and the students would have been repeatedly asked by the schools to make up their mind about their future as they neared the end of the secondary course. 
Nevertheless, we believe that our data suggests that what happens during the primarysecondary transition deserves further research.

Finally, in terms of what schools and teachers should do to encourage their students to pursue S\&T studies and careers (Fig. 3), keeping in mind the evolution of age groups within the clusters (Fig. 2), we suggest that priority be given to the first years of the secondary course. Increasing pedagogical variety and involvement, observations, practical work and experiments, field trips, and projects and decreasing oral presentations, the use of textbooks and websites, and participation in science fairs (a, b, c, d, and finterventions, described in Fig. 3) may possibly prevent some students from slipping from cluster 2 to cluster 4. Operating such a shift in a too radical fashion might could, of course, damage cluster 1 or others. It could also be suggested that in the middle/ end of the secondary courses, projects and initiatives linking science to real life and showing students that science is important for real life could improve students' desire to pursue further studies and careers. We believe some confident indifferent would then possibly become average ambitious. This advice should not discount the fact that efforts to sustain students' interest in S\&T should focus on pedagogical variety, active involvement, and methods that have a positive effect on most students. What is more, undue pressure should not be put on students who simply prefer other subjects over S\&T. Freedom of choice is important and other realms of human activity all have moral, social, and functional legitimacies that rival science's legitimacy. But in cases where S\&T would not have benefited of the interest and considerations it deserves, our advice might help schools make administrative and pedagogical choices that benefit students and society.

\section{Conclusion}

In this research, we suggested and showed that a cluster analysis is sometimes more productive than simple correlational studies for determining why students become more (or less) attracted to S\&T studies and careers. We established a valid four-cluster solution, including one fairly populated and unexpected cluster in which students perceive themselves as being good in S\&T but have no real interest in pursuing S\&T. We showed that these students do not grasp the true importance or utility of S\&T for real life. We also showed that the confident enthusiastic students have very different school experiences than the pessimistic dropouts. On one hand, the confident enthusiastic students were exposed to a wider variety of instructional methods and were much more involved. On the other hand, the pessimistic dropouts were mostly exposed to traditional and rather unchallenging instructional methods in their S\&T classes. Some methods were identified as more or less promising.

By analyzing the evolution of cluster populations in age groups and also by looking at other published results that used the same data (Potvin and Hasni 2014a), we suggested that pedagogical efforts at the beginning of the secondary level could prevent students from slipping into a "low self-concept" state. It might also make it easier to convince them of the importance and utility of S\&T (maybe through projects) if a positive perception of the value and usefulness of S\&T could be induced earlier in their school path.

We believe that our results are interesting in that they encourage researchers to consider profiles of students rather than the mere sets of variables that describe them. It is also an opportunity for teachers to learn what makes students different from others so that they can have more influence over them. Our results also confirm other results about the pedagogical preferences of students and the possibilities of non-traditional instruction (Potvin and Hasni 2014b; Swarat et al. 2012), the importance of capitalizing on novelty effects, and the crucial and positive effects of offering students choices and responsibilities in learning itineraries (Christidou 2011). We believe that our 
results also highlight, maybe more clearly than before, the importance of what students think of the utility and role of S\&T in society and in common problems of all sorts (Hulleman and Harackiewicz 2009; Turner et al. 2015). Finally, it suggests somewhat of an original "game plan" for secondary schools who might want to encourage students to consider S\&T studies.

This research nonetheless has important limitations. While some significant and minimally important differences were recorded using robust and validated constructs and tools, others were observed using a single item. It would have been better to have had well-correlated items for each conclusion; however, with things as different as projects and field trips, it would not necessarily have been convincing nor would it have been fair to ask our participants so many repetitive questions. We therefore lowered the signification threshold but this made us more vulnerable to type 2 errors. Another limitation is the fact that this research is transversal and not longitudinal. Therefore, what appears sometimes as causalities must however not be interpreted as such nor should migrations from one cluster to another be seen as how real students evolve. This is why we limited ourselves to very general conclusions about cluster migrations based on our cluster populations. Finally, we must not forget that this research investigated student's perceptions and not actual class frequencies of activities. Perceptions can indeed act as dependent variables which are affected, namely by interest in school $S \& T$. In other words, previous interest in school can affect how students perceive science classes, but they can also cause distortions about what could truly affect their interest or attraction to S\&T studies and careers. Students are indeed probably never completely lucid about what they have experienced in the past nor about what they need in the future. Our hypotheses therefore need to be tested beyond perceptions and confirmed (or infirmed) with systematic observations. What students ask for could be insightful to choose the best activities, but is certainly not the only way of improving things.

In the future, we however believe that clustering methods can offer interesting insight to our field and that further efforts should be made to better understand individual needs. It is of course technically impossible to know each and every student in all their individual complexity, but between this impossible ideal and our methods that merely draw linear links, we believe our research offers a reasonable and interesting compromise.

Acknowledgements Special thanks to the following school boards: Commissions scolaires de Montréal, Rivière-du-Nord, des Hautes-Rivières, des Grandes-Seigneuries, Marie-Victorin, des Hauts-Cantons, des Sommets, de la Région-de-Sherbrooke, and des Patriotes for their financial and organizational help with this project. We would also like to thank Martin Riopel, François Thibault, Ousmane Sy, Jean-Philippe Bolduc, Marie Hélène Bruyère, Amélia Darsigny, Cynthia Paré, Chloé Lemay-Dagenais, Guillaume Malenfant-Robichaud, Kamal Achachi, and Olivier Laforest for their precious help with the data input and analysis.

Open Access This article is distributed under the terms of the Creative Commons Attribution 4.0 International License (http://creativecommons.org/licenses/by/4.0/), which permits unrestricted use, distribution, and reproduction in any medium, provided you give appropriate credit to the original author(s) and the source, provide a link to the Creative Commons license, and indicate if changes were made.

\section{References}

Agranovich, S., \& Assaraf, O. B.-Z. (2013). What makes children like learning science? An examination of the attitudes of primary school students towards science lessons. Journal of education and learning, 2(1), 55-69.

Ainley, M., \& Ainley, J. (2011). Student engagement with science in early adolescence: the contribution of enjoyment to students' continuing interest in learning about science. Contemporary Educational Psychology, 36(1), 4-12. doi:10.1016/j.cedpsych.2010.08.001. 
Allaire-Duquette, G., Charland, P., \& Riopel, M. (2014). At the very root of the development of interest: using human body contexts to improve women's emotional engagement in introductory physics. European journal of physics education, 5(2), 31-48.

Anderhag, P., Wickman, P.-O., \& Hamza, K. M. (2015). Signs of taste for science: a methodology for studying the constitution of interest in the science classroom. Cultural Studies in Science Education, 10, 339-368. doi:10.1007/s11422-014-9641-9.

Baram-Tsabari, A., \& Yarden, A. (2009). Identifying meta-clusters of student's interest in science and their change with age. Journal of Research in Science Teaching, 46(9), 999-1022. doi:10.1002/tea.20294.

Belcheir, M. J. (1998). Age and gender differences in instructional preferences. Montana: Paper presented at the Rocky Mountain Association for Institutional Research, Bozeman.

Bellocchi, A., \& Ritchie, S. M. (2015). "I was proud of myself that I didn't give up and I did it": experiences of pride and triumph in learning science. Science Education, 99(4), 638-668.

Bong, M., Lee, K., \& Yeon-Kyoung, W. (2015). The roles of interest and self-efficacy in the decision to pursue mathematics and science. In K. A. Renninger, M. Nieswandt, \& S. Hidi (Eds.), Interest in mathematics and science learning (pp. 33-48). Washington D.C.: AERA Books.

Christidou, V. (2011). Interest, attitudes and images related to science: combining students' voices with the voices of school science, teachers, and popular science. International Journal of Environmental and Science Education, 6(2), 141-159.

Cohen, J. (1988). Statistical power analysis for the behavioral sciences (second ed.): Routledge

Corpus, J. H., \& Wormington, S. V. (2014). Profiles of intrinsic and extrinsic motivations in elementary school: a longitudinal analysis. The Journal of Experimental Education, 82(4), 480-501. doi:10.1080/00220973.2013.876225.

Durik, A. M., Hulleman, C. S., \& Harackiewicz, J. M. (2015). One size fits some : instructional enhancements to promote interest. In K. A. Renninger, M. Nieswandt, \& S. Hidi (Eds.), Interest in mathematics and science learning (pp. 49-62). Washington D.C.: AERA Books.

Glynn, S. M., Bryan, R. R., Brickman, P., \& Armstrong, N. (2015). Intrinsic motivation, self-efficacy and interest in science. In K. A. Renninger, M. Nieswandt, \& S. Hidi (Eds.), Interest in mathematics and science learning (pp. 189-202). Washington D.C.: AERA Books.

Gottfried, A. E., Felming, J. S., \& Gottfried, A. W. (1994). Role of parental motivational practices in children's academic intrinsic motivation and achievement. Journal of Educational Psychology, 86(1), 104-113.

Hackett, G. (1995). Self-efficacy in career choices and development. In A. Bandura (Ed.), Self-efficacy in changing societies (pp. 232-258). New-York: Cmabridge

Hasni, A., \& Potvin, P. (2015). Student's interest in science and technology and its relationships with teaching methods, family context and self-efficacy. International Journal of Environmental and Science Education, 10(3), 337-366. doi:10.12973/ijese.2015.249a.

Haste, H. (2004). Science in my future: a study of values and beliefs in relation to science and technology amongst 11-21 year olds. London: Nestlé Social Research Programme.

Hidi, S., \& Renninger, K. A. (2006). The four-phase model of interest development. Educational Psychologist, 41(2), 111-127.

Hidi, S., Renninger, K. A., \& Nieswandt, M. (2015). Emerging issues and themes in addressing interest in learning mathematics and science. In K. A. Renninger, M. Nieswandt, \& S. Hidi (Eds.), Interest in mathematics and science learning (pp. 385-396). Washington D.C: AERA Books.

Hulleman, C., \& Harackiewicz, J. (2009). Promoting interest and performance in high school science classes. Science, 326.

Juriševič, M., Vrtačnik, M., Kwiatkowski, M., \& Gros, N. (2012). The interplay of students' motivational orientations, their chemistry achievement and their perception of learning within the hands-on approach to visible spectrometry. Chemitry education research and practice, 13, 237-247. doi:10.1039/c2rp20004j.

Juuti, K., Lavonen, J., Uitto, A., Byman, R., \& Meisalo, V. (2010). Science teaching methods preferred by grade 9 students in Finland. International Journal of Science and Mathematics Education, 8(4), 611-632.

Kaufmanm, L., \& Rousseeuw, P. J. (2009). Finding groups in data: an introduction to cluster analysis. New York: Wiley.

Koballa, T. R., \& Crawley, F. E. (1985). The influence of attitude on science teaching and learning. School Science and Mathematics, 85(3), 222-232. doi:10.1111/j.1949-8594.1985.tb09615.x.

Korpershoek, H., Kuyper, H., \& van der Werf, G. (2015). Differences in students' school motivation: a latent class modelling approach. Social Psychology of Education, 18, 137-163. doi:10.1007/s11218-014-9274-6.

Krapp, A., \& Prenzel, M. (2011). Research on interest in science: theories, methods, and findings. International Journal of Science Education, 33(1), 27-50.

Maltese, A. V., \& Harsh, J. A. (2015). Students' pathways of entry into STEM. In K. A. Renninger, M. Nieswandt, \& S. Hidi (Eds.), Interest in mathematics and science learning (pp. 203-224). Washington D.C.: AERA Books. 
Mau, W.-C. (2003). Factors that influence persistance in science and engineering career aspirations. The Career Development Quarterly, 51(3), 234-243.

Oliver, J. S., \& Simpson, R. D. (1988). Influences of attitude toward science, achievement motivation, and science self-concept: a longitudinal study. Science Education, 72(2), 143-155.

Olsen, R. V., \& Lie, S. (2011). Profiles of students' interest in science issues around the world: analysis of data from PISA 2006. International Journal of Science Education, 33(1), 97-120. doi:10.1080/09500693.2001.51.8638.

Owen, S., Dickson, D., Stanisstreet, M., \& Boyes, E. (2008). Teaching physics: students' attitudes towards different learning activities. Research in Science \& Technological Education, 26(2), 113-128.

Potvin, P., \& Hasni, A. (2014a). Analysis of the decline in interest towards school science and technology from grades 5 through 11. Journal of Science Education and Technology, 23(6), 784-802. doi:10.1007/s10956014-9512-x.

Potvin, P., \& Hasni, A. (2014b). Interest, motivation and attitude towards science and technology at K-12 levels: a systematic review of 12 years of educational research. Studies in Science Education, 50(1), 85-129. doi:10.1080/03057267.2014.881626.

Renninger, K. A., \& Hidi, S. (2011). Revisiting the conceptualization, measurement and generation of interest. Educational Psychologist, 46(3), 168-184.

Robnett, R. D., Chemers, M. M., \& Zurbriggen, E. L. (2015). Longitudinal associations among undergraduates' research experience, self-efficacy, and identity. Journal of Research i Science Teaching, 52(6), 847-867. doi:10.1002/tea.21221.

Singh, K., Granville, M., \& Dika, S. (2002). Mathematics and science achievement: effects of motivation, interest, and academic engagement. Journal of Educational Research, 95(6), 323-332.

Swarat, S., Ortony, A., \& Revelle, W. (2012). Activity matters: understanding student interest in school science. Journal of Research in Science Teaching, 49(4), 515-537.

Taskinen, P. H., Schütte, K., \& Prenzel, M. (2013). Adolescents' motivation to select an academic science related-career: the role of school factors, individual interest, and science self-concept. Educational Research and Evaluation, 19(8), 717-733. doi:10.1080/13803611.2013.853620.

Turner, J. C., Kackar-Cam, H. Z., \& Trucano, M. (2015). Teachers learning how to support student interest in mathematics and science. In K. A. Renninger, M. Nieswandt, \& S. Hidi (Eds.), Interest in mathematics and science learning (pp. 243-257). Washington D.C.: AERA Books. 